Portland State University

PDXScholar

1974

\title{
An Investigation of Tympanometric Measurements on an Older Adult Population
}

Marguerite Ann Fine

Portland State University

Follow this and additional works at: https://pdxscholar.library.pdx.edu/open_access_etds

Part of the Speech Pathology and Audiology Commons Let us know how access to this document benefits you.

\section{Recommended Citation}

Fine, Marguerite Ann, "An Investigation of Tympanometric Measurements on an Older Adult Population" (1974). Dissertations and Theses. Paper 2173.

https://doi.org/10.15760/etd.2170

This Thesis is brought to you for free and open access. It has been accepted for inclusion in Dissertations and Theses by an authorized administrator of PDXScholar. Please contact us if we can make this document more accessible: pdxscholar@pdx.edu. 
AN ABSTRACT OF THE THESIS OF Marguerite Ann Fine for the Master of Science in Speech with emphasis in Speech Pathology and Audiology presented November 19, 1972.

Title: An Investigation of Tympanometric Measurements on an Older Adult Population.

APPROVED BY MEMBERS OF THE THESIS COMMITTEE:
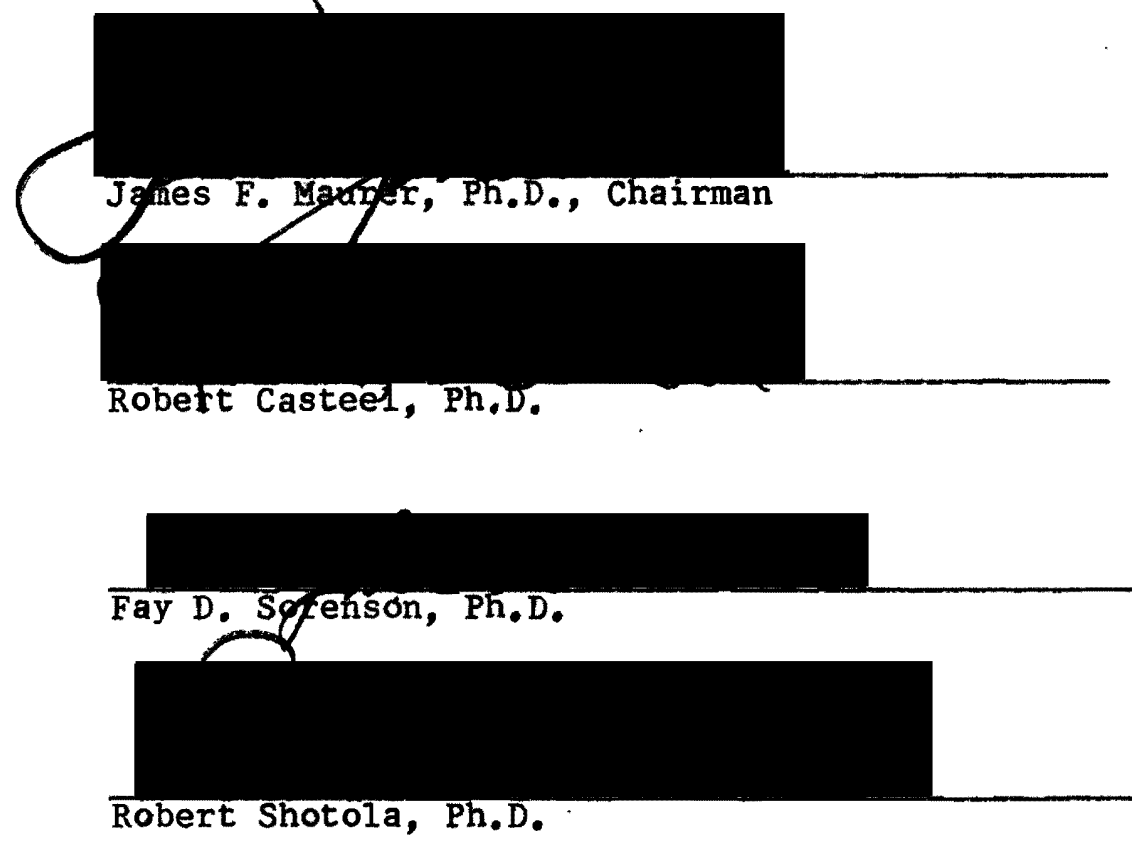

Prior to this investigation, there appeared to be no published research data available on tympanometric configurations obtained from an older adult population. This study was designed to examine tympanograms obtained from an otologically normal, elderly population. Forty individuals, ranging in age from 59 to 83 years, participated in this study. All had a negative history of middle ear pathology and had normal tympanic membranes as determined by otologic examination. From 
the eighty ears tested, fifty were used in this survey. Conductance and susceptance at 220 and $660 \mathrm{~Hz}$ were obtained at each ear and ranges for admittance were computed from these components. Additionally, acoustic reflex thresholds were obtained from this population. The results obtained indicate that the values for the measures of conductance and susceptance are comparable to those from young adult groups. The reflex thresholds are slightly higher in the older group because their hearing thresholds are not as acute as those found in younger populations. Finally a larger percentage of the older population than might be expected was found to have evidence of healed perforations which were not discovered during otoscopic examination.

The present investigation demonstrated that additional normative data are needed in order that the otoadmittance meter be fully utilized with older adult populations. 
AN INVESTIGATION OF TYMPANOMETRIC MEASUREMENTS

ON AN OLDER ADULT POPULATION

by

MARGUERITE ANN FINE

A thesis submitted in partial fulfillment of the requirements for the degree of

MASTER OF SCIENCE

in SPEECH

WITH EMPHASIS IN SPEECH PATHOLOGY AND AUDIOLOGY

Portland State University

1974 
TO THE OFFICE OF GRADUATE STUDIES AND RESEARCH:

The members of the Committee approve the thesis of

Marguerite Ann Fine presented November 19, 1974.

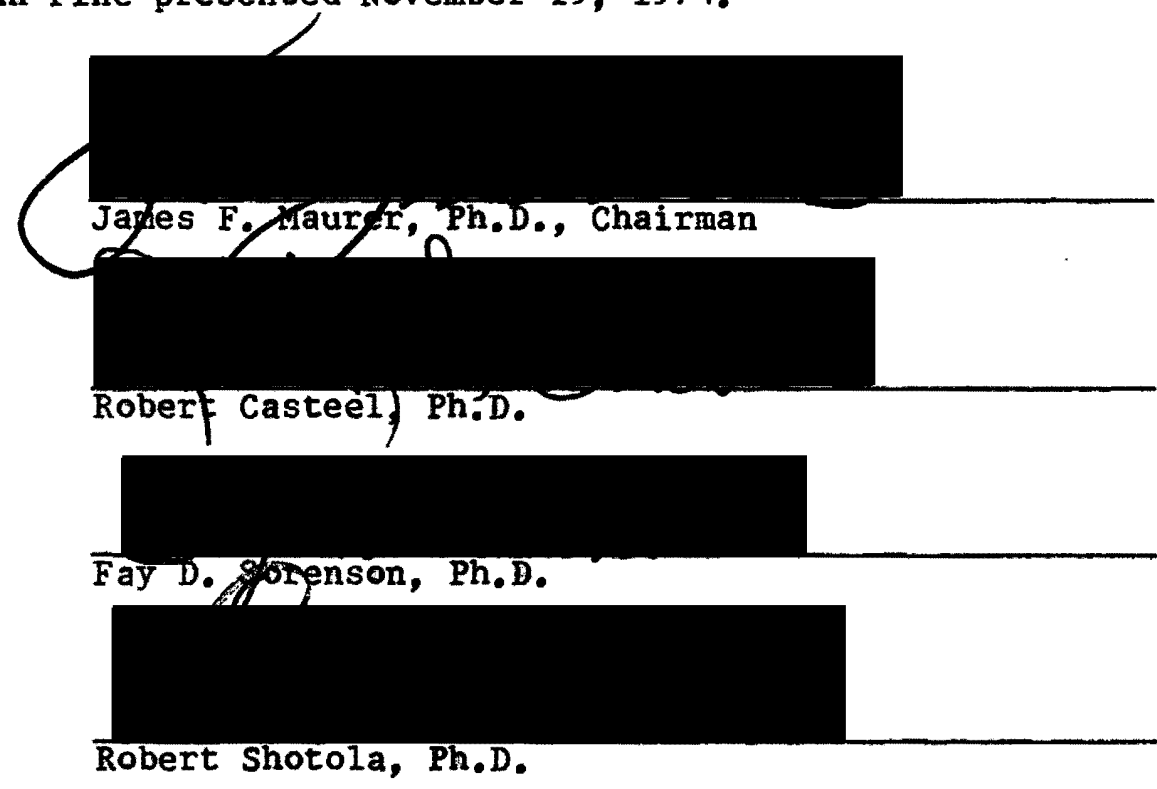

APPROVED:

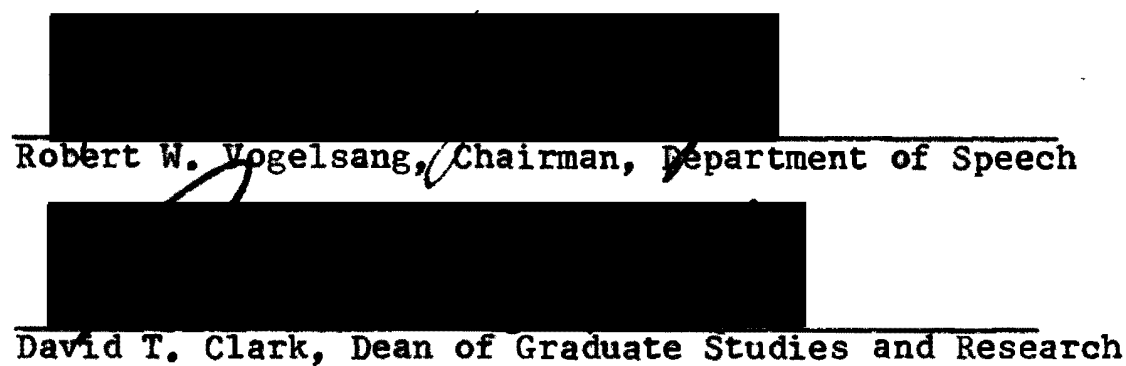

November 25, 1974 


\section{ACKNOWLEDGMENTS}

I wish to express by appreciation to those who have been so helpful to me in completing this study. To Dr. James F. Maurer, my thesis difector, my sincere gratitude for the support and encouragement he provided during this investigation. Thanks also to my thesis committee members, Dr. Robert Casteel, Dr. Fay Sorenson, and Dr. Robert Shotola, for their interest and guiding comments.

Special thanks go to Mr. Michael Fairchild and Dr. Q.D. Clarkson for their statistical expertise, and to $\mathrm{Dr}$. Steven Fausti of the Veterans Hospital of Portland, Oregon, for his advice and recommendations.

I am most grateful to the Portland State University Research and Publications Committee for financial assistance for this study and I wish to acknowledge the support and guidance afforded by the Institute on Aging, Portland State University.

Finally, to my husband Wayne, my deepest thanks -- for his patience and his unfailing support and belief in me. 
TABLE OF CONTENTS

\section{PAGE}

ACKNOWLEDGMENTS ................... ii

IIST OF TABLES ........................ vi v

IIST OF FIGURES ........................ vii

\section{CHAPTER}

I INTRODUCTION .................. 1

statement of Purpose ........... 2

II REVIEW OF THE LITERATURE ............. 3

Middle Ear Muscle System ......... 4

Sound Transmission in the Ear ......... 5

Clinical Methods of Measuring Acoustic Impedance ................ 6

Impedance Measurements . . . . . . . 8

Tympanometry ............... 9

Reflex Measurements .......... 10

Normative Standards ........... 11

Diagnostic Implications .......... . 12

Changes in Hearing Associated with Aging ... 13

II MEIHOD

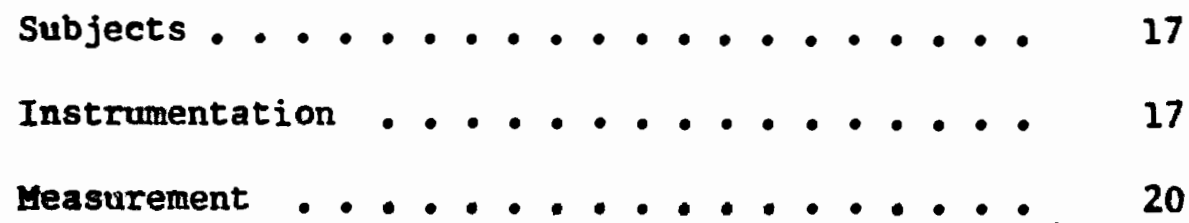


CHAPTER

PAGE

Test Procedure ................ 21

Betesting ................ 22

IV RESULTS AND DISCUSSION . . . . . . . . . 24

Results ................. 24

Discussion ............... 29

Clinical observations ......... 31

Research Implications .......... 34

v SUMMARY AND CONCLUSIONS ............. 35

REFERENCES ........................

37 


\section{LIST OF TABLES}

TABLE

PAGE

I Ranges of Hearing Levels by Age Groups and Sex of

Selected 01der Adults (Goetzinger, et al., 1961) .. 15

II Susceptance, Conductance, Admittance in Mmhos and

Impedance in Ohms: Medians and Ranges . . . . 26

III Group Data for Conductance, Susceptance, Admittance

in Millimhos, and for Impedance in Ohms ....... 27

IV Group Data for Acoustic Reflex Thresholds . . . . . 28

v 10 Normal Ears: Test - Retest ........... 30 


\section{LIST OF FIGURES}

FIGURE

PAGE

1 Schematic illustration of the Zwislocki Acoustic Bridge (Lamb and Norris, 1969) .........

2 Typical pressure-compliance curves illustrating results of tympanometry with a normal ear and with a case of otitis media (Lamb and Norris, 1969) .....................

3 Schematic representation of the Grason-Stadler

Otoadmittance Meter Model 1720 (Porter, 1972) •.

4 Ranges of 50 normal ears obtained from an older adult population. ...................

5 Tympanogram resulting from a healed perforation

(Otoadmittance Handbook 2,1973$)$........ 


\section{CHAPTER I}

\section{INTRODUCTION}

A relatively recent contribution to the field of audiometry has been the introduction of electroacoustic measuring instruments designed to evaluate middle ear functioning. This technique of measuring, recording, and evaluating changes in the tympanic membrane and middle ear cavity under conditions of varying air pressure has been termed tympanometry.

Prior to the introduction of the electroacoustic measurenent instruments, it was difficult to determine the function of separate parts of the auditory system. With the electroacoustic bridge, the measurements can be restricted to a specific portion of the auditory system - the middle ear. With this instrument, it has become possible to demonstrate acoustic manifestations of various pathological conditions in the middle ear, such as otosclerosis, otitis media, and ossicular discontinuities.

During the aging process, a certain amount of anatomical and physiological change takes place in the middle ear, involving the ligaments, muscles, and connective tissue. These changes, which are a result of the aging process, may cause a variety of lesions which are conductive in nature (Goodhil1, 1969). There appears to be no published research data available on tympanometric configurations obtained from an elderly population. The establishment of tympanometric patterns common to the elderly should enhance the information now 
available for clinical and research purposes.

Statement of Purpose

The purpose of the present study is to examine by the use of tympanometry, configurations obtained from an otologically normal, elderly population. Using the two probe tones of the Grason-Stadler Model 1720, the components of admittance -- conductance and susceptance -- will be investigated in order to gather data which may be used toward establishing working normative values. The information gathered will be compared with norms established for an otologically normal young adult population (Feldman, 1974; Jacobson, et al., 1973; Dirks and Morgan, 1973; and Porter, 1972), and the following question will be investigated: What are the differences, if any, between tympanograms obtained from a normal young adult sample and those obtained from a normal older adult sample.

It is hoped that the information obtained from this study will add to the diagnostic usefulness of tympanometry among older age groups. 
REVIEW OF THE LITERATURE

The traditional approach to hearing assessment routinely includes the comparison of pure tone air-conduction thresholds with bone-conduction thresholds. The presence or absence of an air-bone gap yields information regarding the status of the middle ear, but gives little or no information regarding the cause of any conductive problems. In addition, audiometric tests rely. primarily upon the patient's subjective decisions regarding the presence of the pure-tone stimuli. An otoscopic examination is limited to an inspection of eardrum mobility at extreme amplitudes of motion and gives inconclusive results in cases of conductive hearing loss, except those that are associated with gross changes in the anatomy, position, or mobility of the eardrum (Lamb and Norris, 1969; Zwislocki and Feldman, 1970).

The development of impedance measurements has provided a quantitative and objective measurement of middle ear functioning and has supplied a means of restricting these measurements to the middle ear only. It is now possible, through the use of impedance measurements, to detect middle ear pathologies that may not surface during otoscopic and audiometric examinations, and further, to differentiate among the various disorders (Metz, 1946; Zwislocki, 1957, 1961, 1963; Terkildsen and Nielsen, 1960; Lamb and Norris, 1969; and Zwislocki and Feldman, 1970). 
Middle Ear Muscle System

In order to better understand the bases of impedance measurements, a knowledge of the functioning of the middle ear system is necessary. The tensor tympani and the stapedius, muscles in the middle ear, contract in response to sounds of loud intensity. The tensor tympani is attached to the malleus (one of the three ossicles in the middle ear cavity). It is innervated by the Vth Cranial or Trigeminal Nerve and contraction of the tensor tympani draws the malleus medially and anteriorly. The stapedius muscle attaches to the neck of the stapes (another of the ossicles), is innervated by the VII or Facial Nerve and upon contraction, draws the stapes outward and backward from the oval window, counteracting the opposite pull of the tensor tympani. These muscles have two opposing functions: first, to increase the sensitivity of the tympanic membrane and the ossicular chain to sounds of weak intensity, and second, to protect the inner ear from sounds of unusually loud intensity by reducing the mobility of the ossicular chain, thus decreasing the efficiency of sound transmission (Zemlin, 1968; Lamb and Norris, 1969; Davis and Silverman, 1970; Newby, 1972) although this latter function is now in question (Jerger, 1974). The contraction of the muscles of the middle ear in response to loud sound, termed "acoustic reflex," usually is elicited at sound intensities well above the threshold for hearing. In man, it is elicited at intensities ranging from $80-90 \mathrm{~dB}$ above the pure-tone threshold for hearing, with the lowest reflex threshold corresponding in frequency to the lowest threshold for hearing (Jepsen, 1963). Luscher (cited by Jepsen, 1963) used tones throughout the frequency 
range of 90 to $14,000 \mathrm{~Hz}$ to demonstrate reflex activity and found that the most sensitive frequency for eliciting the reflex was $2,000 \mathrm{~Hz}$.

The muscle contraction is set off by a reflex action from the lower centers of the brain a few hundredths of a second after the sound reaches the eardrum. This reflex results in a modicum of protection against possible damage by large amplitudes of movement to the middle ear and the inner ear. Moreover, there is a latency between the time that the sound impinges upon the tympanic membrane and the contraction of the muscles. Wever and Lawrence (1954) cite mean latency values of .06 seconds for the stapedius and .15 seconds for the tensor tympani. This factor places a real limitation upon the "protection" that the tympanic muscles can provide to the middle and inner ears.

More recent studies have indicated that it is probably the stapedius muscle alone that responds to sound with a recordable reflex; therefore, many authors prefer to use the term "stapedius reflex" in conjunction with middle ear reflex action (Klockhoff, 1961; Jepsen, 1963; Feldman, 1967, Jerger, 1974). Most authors agree that the most efficient way of measuring reflex activity in man is through the use of relative impedance methods.

Sound Transmission in the Ear

Before describing the principles of impedance measurements, it may be beneficial to consider the propagation of sound in the normal ear. When an acoustic wave reaches the tympanic membrane, the greater part of its energy is reflected and a portion produces a vibration of the eardrum. This latter part is transmitted via the ossicular chain through the oval window to the inner ear. The reflected energy forms 
a wave that is propagated outward from the tympanic membrane. Its frequency is identical to that of the incident wave. However, its phase and amplitude are dependent upon the impedance at the eardrum, which in turn, is controlled by the properties of the membrane, ossicular chain, ligaments and muscles of the middle ear, the oval and round windows, the middle ear cavity, and the interconnected pneumatic cells. Therefore, the sound wave reflected at the tympanic membrane carries information concerning the state of the entire middle ear (Zwislocki, 1961).

\section{Clinical Methods of Measuring Acoustic Impedance}

The concept of acoustic impedance was introduced by A.G. Webster in 1914, but was not widely utilized until Metz (1946) adapted these principles for use in the development and construction of the acoustic bridge. He was able to demonstrate that various pathological middle ear conditions produce different and distinct patterns of impedance. The Metz Bridge, however, was unwieldy, difficult to use, and did not yield stable measurements. Furthermore, the bridge could not control the effect of the volume of the ear canal on the measurement. It was not until the reports of Zwislocki (1963) and Feldman (1963) that the use of the acoustic bridge for measuring impedance provided meaningful information for the differential diagnosis of auditory disorders. The Zwislocki Acoustic Bridge, shown schematically in Figure 1; is based upon the same principles as those described by Metz. However, this instrument included a means by which the effects of the volume of the ear canal could be eliminated from the measurement. This was accomplished by filling the ear canal with alcohol from a calibrated 
syringe. Volume $v_{1}$ on the instrument is set to the measured volume of the canal as shown on the syringe.

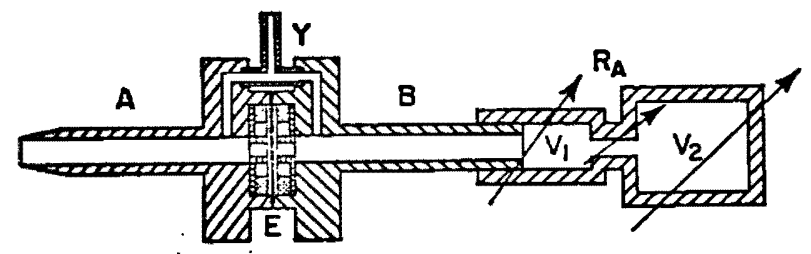

Figure 1. Schematic illustration of the Zwislocki Acoustic Bridge (Lamb and Norris, 1969).

The Bridge consists of two main tubes ( $A$ and $B$ ) of equal internal diameter and length with an electro-acoustic transducer ( $T$ ) mounted between them. The monitor tube ( $Y$ ) leads to the examiner's ears. Tube A is connected to the ear canal via a speculum; tube B terminates in the matching impedance. The transducer ( $T$ ) presents sound waves of equal amplitude, but opposite phase into the two main tubes. These waves are partially reflected at the ends of each tube and the resultant sound pressure in each tube is generated by both the original and the reflected waves. The sound pressure in both tubes is equal when both are terminated by an equal impedance. A null or cancellation of sound occurs as a result of the phase opposition, and can be detected by mitoring the $\mathrm{Y}$ tube. When this occurs, the impedance at the end of the tube (B) is equal to the unknown impedance of the tympanic membrane and the middle ear, and may be read directly from the variable controls, $v_{2}$ (compliance element) and $R_{A}$ (resistance element).

Two additional tests may be performed: tactile stimulation around the tragus of the test ear, or introduction of noise or tone to the contralateral ear. The presence of the stapedius reflex will re- 
sult in a return to the probe tone (a loss of the null or sound cancellation) as monitored by the examiner. The null returns when either mode of stimulation ceases (Feldman, 1963).

Both the Metz and the Zwislocki Bridges used ambient air pressure to measure acoustic impedance. In 1960, Terkildsen and Neilsen developed an electroacoustic bridge which provided a source of air pressure that was continuously variable from a negative value, through zero, to a positive value. The two electroacoustic bridges developed for clinical use are the American Electroacoustic Impedance Meter (formerly, the Madsen Acoustic Impedance Meter) and the Grason-Stadler Otoadmittance Meter, using the balancing system originally introduced by Terkildsen and Nielsen (1960). Nearly all of the research data available at this time concerns the use of the Madsen Acoustic Impedance Meter, notably the work of Brooks (1968, 1969, 1971), Jerger (1970), and Lilly (1973).

\section{Impedance Measurements}

The measurement under consideration is the extent to which the tympanic membrane is resistant to movement and opposes the sound pressure changes. This opposition to change, or resistance to motion, represents the acoustic impedance of the ear. In other words, acoustic impedance may be defined as the opposition by a surface to the flow of acoustic energy through that surface. Three components may interfere with or impede the flow of acoustic energy, stiffness, mass, and resistance. Stiffness in the middle ear is produced by the tympanic membrane, the ligaments and muscles of the middle ear, the volume of air in the middle ear, and the cochlear windows. Mass is determined by the weight of the ossicular chain; the resistance is determined by the in- 
put impedance of the cochlea and to some extent, by the frictional resistance of the ossicles (Zwislocki, 1963).

When the middle ear system is unusually stiff, as in the presence of otosclerosis, the tympanic membrane presents a greater than normal resistance to motion; that is, it is less compliant. Little sound energy is transmitted through the middle ear system, and a greater than normal amount is reflected from the membrane. This condition is said to have a high impedance factor. In an ear with ossicular discontinuity, the membrane is extremely compliant, with a large amount of energy absorbed by the membrane and little reflected back into the external auditory meatus. This condition shows extremely low acoustic impedance (Feldman, 1963).

\section{Tympanometry}

The concept of tympanometry may be defined as a technique for measuring, recording, and evaluating changes in acoustic impedance with systematic changes in air pressure. The relationship between changes in acoustic impedance and changes in air pressure is affected by middle ear pathologies, perforations of the tympanic membrane or scars of the membrane, or by abnormal air pressures in the middle ear. For example, if fluid is present in the middle ear, the point of maximum compliance will be displaced and the degree of compliance reduced. Figure 2 compares a normal and a pathological tympanometric curve.

Conditions such as otosclerosis and ossicular chain discontinuity appear as changes in the compliance of the tympanic membrane, but show no pressure anomalies. Otosclerosis causes the conductive system to be stiff or non-compliant, while an interruption in the ossicular chain or 
a scarred tympanic membrane results in abnormally high compliance. Negative air pressure in the middle ear cavity produces a curve displaying a shift to the left of $0 \mathrm{~mm} \mathrm{H} \mathrm{H}_{2} \mathrm{O}$, and a shift of $100 \mathrm{~mm} \mathrm{H}_{2} \mathrm{O}$ or more is associated with Eustachian tube malfunction. An ear which

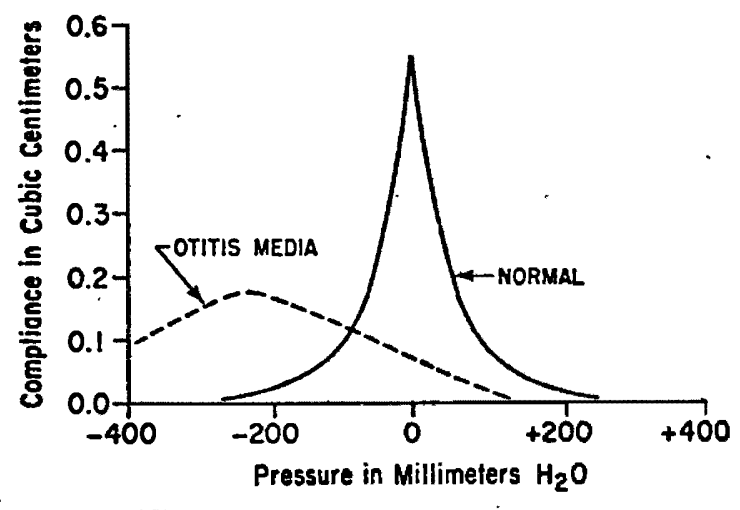

Figure 2. Typical pressure-compliance curves iliustrating results of tympanometry with a normal ear and with a case of otitis media (Lamb and Norris, 1969).

contains fluid also displays a negative curve configuration. Because of the stiffening influence of the fluid, the tympanic membrane will not achieve normal compliance and thus can be differentiated from the other curves (Lamb and Norris, 1969; Lamb, 1971; Lilly, 1973).

\section{Reflex Measurements}

In a normal middle ear, contraction of the stapedius or the tensor tympani muscle produces a "measurable, time-locked change in acoustic impedance at the lateral surface of the tympanic membrane" (Lilly, 1973). With the use of electroacoustic instrumentation, reflex measurements are termed relative acoustic impedance measurements. The threshold of the acoustic reflex is that sensation level at which a 
sound is just capable of eliciting a reflex contraction. The reflex threshold falls within a predictable range of intensities, adding to the diagnostic usefulness of impedance measurements (Lamb and Norris, 1969). Jepsen (1963) reported studies of the acoustic reflex to pure tones in normal subjects ranging in age from ten to eighty years. He found that while the auditory thresholds were poorer in the older subjects as compared to the younger group, there was an increase in the sensitivity of the acoustic reflex thresholds. This change occurred at each frequency, but was more pronounced above $1000 \mathrm{~Hz}$. For example, at $4000 \mathrm{~Hz}$, the range between thresholds was reduced to $15 \mathrm{~dB}$ for the eighty year old subjects. This reduced range is assumed to be a manifestation of loudness recruitment, resulting from cochlear dysfunction. Although the absence of the stapedius reflex usually indicates middle ear pathology, the reflex cannot always be elicited. There appears to be a very small percentage of otherwise normal individuals who do not show the acoustic reflex at any level. When the reflex is elicited acoustically, the success depends upon a sufficiently low hearing level. The absence of the reflex does not always indicate the presence of a middle ear disorder, nor does a detectable reflex contraindicate the presence of pathology. The reflex has been found in some sites of ossicular discontinuity and serous otitis media. Thus, although relative impedance does not always give a true diagnostic picture, when used in combination with tympanometry, a correct diagnosis can be made (Robertson et al., 1968; Jerger, 1970; Zwislocki, 1970).

\section{Normative Standards}

Feldman (1974) established normative tympanometric curves with 


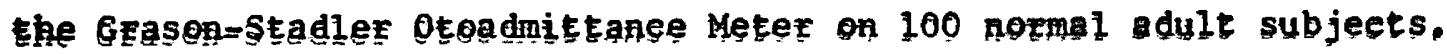
These subjeets had no otologiealiy eonfizmed middige eax involvement and

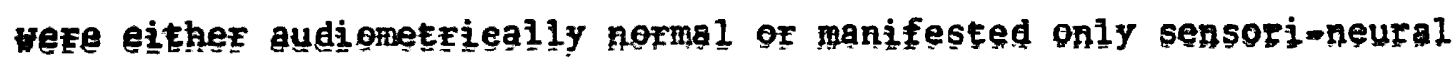
impaiment, Đixks and Moxgan (1973) established nomative data on 52 subjgees, Poftex (1972) established normațive otoadmittance values for 18 zoxmal hearing adults, Jaegobson, et al.,(1973)developed normative 8tandazds fox elinieal use of the otoadmittance Meter by eqndueting Eympangmetry on 30 nofmal young adultss. The data gathered by these Eesearehers are displayed on Tables II and III (pages 26 and 27).

\section{Diagnestie Implieations}

Tympanemeţ has beeome, in thany elinies, an invaluable diagnostic Eogl and a reutcine part of the audiologieal assessment of every patient. The pxpeedure is reasonabiy simple and rapid and has been used suecessfully with persons of al1 ages, Jergex (1970) repofts on the use of Eympangmetey with infants, and Brogks (1968, 1971) has used this method gueeessfuliy on sehogl age ehịdren, Beeguse sţandaft proeedures using gure=tene air $=$ and bone=enduetion audienetry are oftęn diffieult to administer, Eympanomeţry has bẹen found to be of value with mentally EeEarded patienț beeause enly passive cooperation is fequired of the subjẹet (Lamb and Norris, 1969). In addittion, there appears to be a higher than normal ingidenee of eonduetive disorders among the mentally fetardẹd, therefore, tympanometrie measurements may be partieularly useful.

AlEhough Eympanometrie methods in elinieal praetiee have been in use fer glightly mefe than a degade, little information has been found on theif use with the elderly. A possible reason for this might be 
that because tympanometry is used to evaluate middle ear pathologies and hearing loss in the elderly is primarily a sensori-neural impairment, there appeared to be little reason to employ this instrumentation. Hinchcliffe (1962), in a personal communication with A. Mbller, quotes Mpller as stating that changes in the acoustic impedance of the middle ear as a function of age have not been noted. Tympanometry was used on 316 patients of all ages by Jerger (1970). Of this number, fiftyfive subjects were sixty years of age or over, or seventeen percent of the total population. However, none had normal hearing sensitivity and a conductive or sensorineural component was present in all of these subjects.

Changes in Hearing Associated with Aging

It is well known that there is a change in hearing level with age and this gradual reduction in hearing sensitivity associated with increased age has been termed "presbycusis." In most cases, both ears are affected at about the same rate and the loss occurs gradually over the years.

In the earliest stages of presbycusis, only the epithelial elements in the cochlea may be affected. At this point, the impairment is classified as sensory in origin. Later, the nerve elements become involved and the classification is thought to be sensori-neural. Finally, the cortex and the central pathways become involved and the condition is classified as a central hearing impairment, or central dysacusis. In other cases, the nerve fibers appear to be damaged and the impairment is conșidered to be primarily a neural hearing impairment (Sataloff, 1966). 
Although presbyeusis is generally ennsidered to be sensorineural impairment, Glofig and Davis (1961) identifięd a conductive element, whose presence was indieaţeg by an aifmbone gap. They labeled this type "conduetive prespyeusis." In theiz sample of elderly who had no noise exposure that eould be judged as severe by modern standards, the ohift in threshold sensitivity due to presbyeusis had an appreeiable conductive element. The preeise eontzibution that this high tone eonductive loss makes to presbyeusis in the general population is not yet clear.

Goodhill (1969) ușed the same tẹm (eonduețive presbyeusis) to identify the changes found in the middle ear as a result of aging. He atated that the term "presbycusign" should not be limited to losses of a censori-neural nature. If aging proeesses oeeur in the ligaments and muscles and connective tissue, then it is possible and quite likely that changes due to senescenee may oeeur in the middle ear involving the ossicular chain and the Eympanie membrane. These ehanges, which may be normel or premature, may eause a varietyy of aging lesions which are not sensori-neural, but conduetive in nature.

According to Hineheliffe (1962), Ehresholds in the elderly show a departure from the basie presbyeusie trend and portray a hearing loss greater than the predieted loss. The dișerepaney between predieted and actual thresholds is greater with tones of higher frequency and with increasing age. It is possible, then, that "the high frequency conductive loss could aceount for this digerepaney and constitute a major secondary factor in the deteriopation of the auditory threshold with "ge" (Hinchcliffe, 1962).

Gootzinger, et al. (1961) established eurves of average hearing 
levels for men and women from ages 60 to 90 inclusive. The criteria for selection of a subject included no history of hearing loss prior to age fifty, he must have been relatively free from ear infections during life, and have had relatively little exposure to noise. They found that hearing level decreases as a function of increasing age, that men have more acute hearing in the lower frequencies and women in the higher frequencies, and that the hearing level for both men and women drops off markedly for the higher frequencies with increased age. Table I shows the means, standard deviations, and ranges for the pure tone air-conduction thresholds by age and by sex.

TABLE I

RANGES OF HEARING LEVELS BY AGE GROUPS AND SEX OF SELECTED OLDER ADULTS. THESE HEARING LEVELS IN dB re ISO-1964 AUDIOMETRIC ZERO WERE COMPUTED FROM SOUND PRESSURE LEVELS PRESENTED BY GOETZINGER, et al. (1961)

Frequencies in $\mathrm{Hz}$

\begin{tabular}{|c|c|c|c|c|c|c|c|c|c|c|c|c|}
\hline Age & Sex & & 250 & & 500 & & 000 & & 000 & & 40 & 00 \\
\hline $\begin{array}{l}60-69 \\
n=15\end{array}$ & $\mathbf{M}$ & -10 & to 20 & -10 & to 26 & -10 & to 30 & -10 & to & 51.5 & 4 & to 6 \\
\hline$n=15$ & $\mathbf{F}$ & -10 & to 10 & -10 & to 11 & -10 & to 15 & -8 & to & 31.5 & -4 & to 5 \\
\hline $\begin{array}{l}70-79 \\
n=15\end{array}$ & $\mathbf{M}$ & -10 & to 5 & -10 & to 21 & -10 & to 30 & -10 & to & $56: 5$ & 19 & to 6 \\
\hline$n=15$ & $F$ & -10 & to 15 & -10 & to 16 & -10 & to 35 & -3 & to & 46.5 & 9 & to 6 \\
\hline $\begin{array}{l}80-89 \\
n=15\end{array}$ & $\mathbf{M}$ & -10 & to 25 & -4 & to 31 & 0 & to 35 & 6.5 & to & 56.5 & 44 & to 8 \\
\hline$n=15$ & $\mathbf{F}$ & -5 & to 30 & -9 & to 26 & 0 & to 30 & -3 & to & 36.5 & 14 & to 9 \\
\hline
\end{tabular}

Binchcliffe (1962) reported on studies by Fleischer and by Crowe, et al. who state that presbycusis is predominantly a "ganglion type" deafness. In other words, atrophy of the spiral ganglion cells occurs 
in later years. Hinchcliffe observed that threshold shifts due to aging begin at an early age and atrophy of the spiral ganglion cells appear much later in life. In many cases, elderly people have had considerable threshold shifts due to aging, but have shown no histological changes in either the organ of Corti or in the spiral ganglion. Goetzinger, et al. (1961) studied men and women between the ages of eighty and one hundred who showed no significant tone decay. They concluded that the degenerative changes in the cochlea and in the second-, third-, and fourth-order neurons are not dominant factors in the development of presbycusis.

The conclusions drawn from Hinchcliffe's exhaustive review of the 1iterature regarding changes in the aging auditory system indicate that although degenerative changes contribute to presbycusis, it is more likely that changes in the brain are primarily responsible for the overall effect of presbycusis. "The relative contribution of the degenerative changes in different anatomical loci to changes in a given audiologic measure is variable and dependent upon the particular measure involved" (Hinchcliffe, 1962). 


\section{CHAPTER III}

METHOD

In order to gather data which may be used toward establishing working norms on tympanometric curves obtained from an elderly population, the following methods and procedures were utilized.

\section{Subjects}

Forty subjects who, upon screening, were classified as "normal older adults" were chosen to participate in this study. The majority of the subjects were selected from among those individuals who had been screened by Project ARM (Auditory Rehabilitation Mobile), sponsored by Portland State University. The following criteria were employed to select subjects suitable for this study: 1) over fifty-nine years of age; 2) auditory acuity commensurate with his age (Goetzinger et al., 1961): 3). negative history of middle ear pathology; 4) normal tympanic membranes as determined by otologic examination.

The ages of the forty subjects ranged between fifty-nine and eighty-three years of age, mean age $=69.8$. Only those tympanograms in which maximum values fell within $\pm 50 \mathrm{~mm} \mathrm{H}_{2} \mathrm{O}$ of ambient pressure were included. Tympanometry was performed on both ears of each subject; however, if one ear presented an abnormal tracing, only the other "normal" ear of the subject was included in this study.

\section{Instrumentation}

The Grason-Stadler Otoadmittance Meter (Model 1720) consists of 


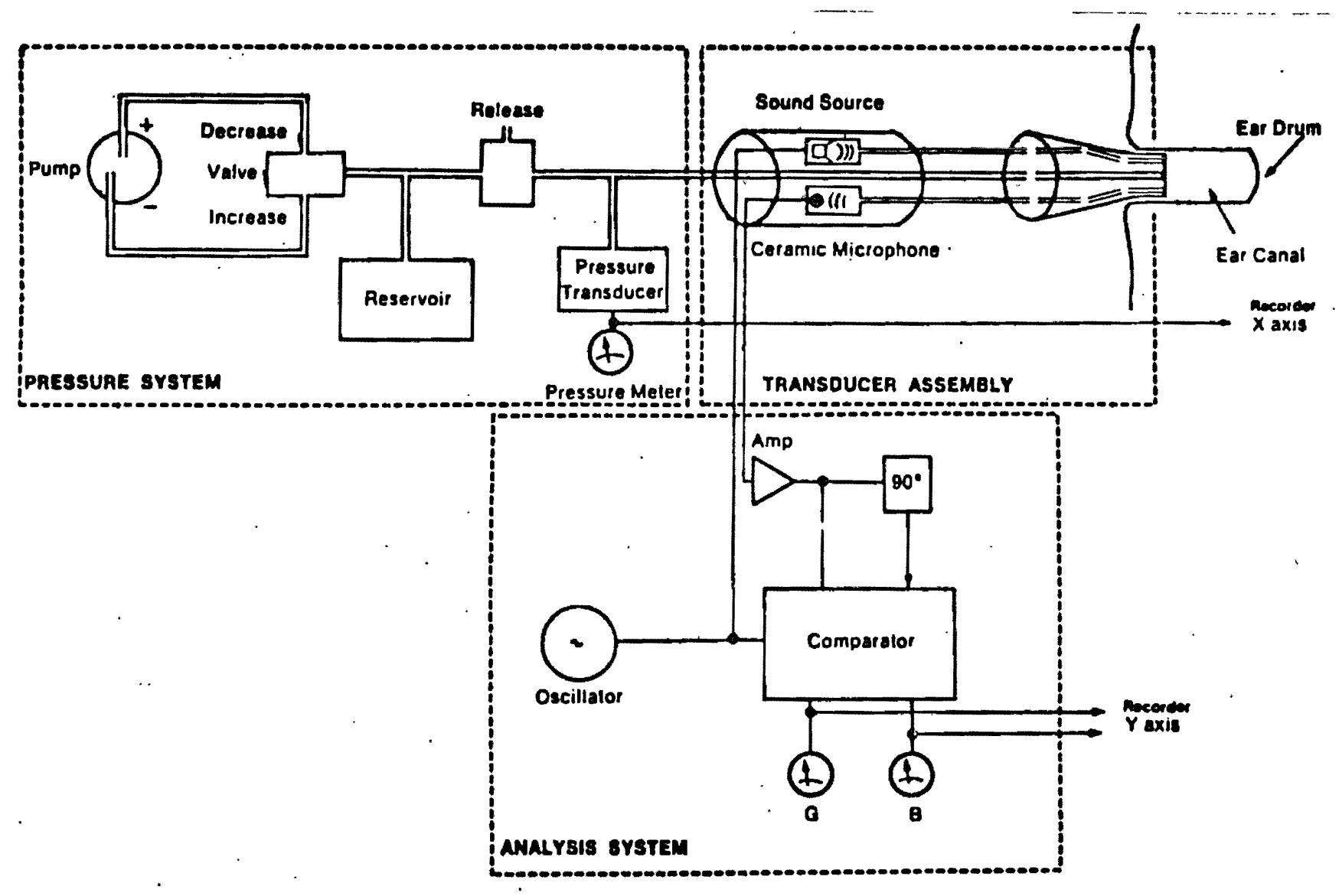

Figure 3. Schematic representation of the Grason-Stadler Otoadnittance Meter, Mode1 1720 (Porter, 1972. 
three subassemblies (see Figure 3): one for the control of air pressure, one for the generation and monitoring of sound waves, and one for the electronic control and evaluation of the input sound flow and the output sound pressure conditions.

The air pressure system presents a continuously variable positive or negative air pressure to the ear canal and this feature permits the stiffening of the tympanic membrane in order to estimate the conductance and susceptance of the ear canal. The transducer or driver/ monitor assembly, consisting of an earphone driver and ceramic microphone, is mounted in a housing connected to the earpiece. Sound energy is introduced into the ear canal, modified by the conditions it encounters in the canal and at the tympanic membrane, and is picked up by the microphone. The analysis system maintains a constant sound pressure level of approximately $85 \mathrm{~dB}$ SPL at the tympanic membrane, regardless of conditions found there.

The sound flow required to maintain constant pressure in the ear canal is $90^{\circ}$, out-of-phase with the pressure, if the ear is free of energy loss. Energy losses result in an in-phase component. The inand out-of-phase components are measured separately and may be read directly on the two meters as susceptance and conductance, expressed in millimhos (Otoadmittance Handbook 2, 1973).

The voltages representing conductance and susceptance are available to drive an $X-Y$ plotter from the rear of the instrument, as well as a voltage which is proportional to the air pressure in the ear canal. A graphic record can then be made depicting the relationship between compliance changes as a function of variation of pressure in the ear canal (Parter, 1972). Thus a tympanogram is generated whose charac- 
teristic pattern is diagnostically invaluable.

\section{Measurement}

The unit of measurement under consideration is admittance, or ease of energy flow, which is the reciprocal of impedance. The components of impedance, resistance and reactance, are termed conductance $\left(G_{A}\right)$ and susceptance $\left(B_{A}\right)$ respectively. Conductance is a measure of energy flow through resistance while susceptance is a measure of energy flow through reactance. Susceptance can be equated to compliance, commonly thought of as the reciprocal of stiffness. Using admittance terminology, the unit of admittance is the mho (ohm spelled backward) (Otoadmittance Handbook 2 , 1973).

When the tympanic membrane is stiffened by the introduction of air pressure, the admittance at the drum is approximately zero and the value of admittance is that of the ear canal. When the air pressure is equal on both sides of the drum, the admittance measured is the sum of the admittance of the ear canal and the admittance of the drum. Admittance is said to be the ratio of sound flow to sound pressure and is constant within the ear canal when a low probe tone frequency is used. Sound flow, and therefore admittance, for the tympanic membrane is the difference between the drum tight and the drum loose measurements (Porter, 1972).

Admittance can be calculated according to the following method:

$$
|Y|=\sqrt{G^{2}+B^{2}}
$$

where $Y=$ admittance, $G=$ conductance, $B$ - susceptance. Since adnittance is the reciprocal of impedance $(Z)$, the latter may be determined by the formulas $\quad|z|=\frac{1}{Y}$ (Otoadmittance Handbook 2,1973). 
Test Procedure

Immediately prior to this evaluation, each individual was subjected to an otoscopic examination. When a large amount of cerumen, which precluded viewing the tympanic membrane, was present, the ear was washed out before the examination proceeded.

Pure tone air- and bone-conduction testing were done in a singlewall IAC Model SP 403 room using a Beltone 15-C audiometer. Norms for air conduction audiometry were those established by Goetzinger et al. (1961) for individuals of advanced age. His data, based on ASA-1951 standards were converted to ISO-1964 standards (see TABLE I on page 15). Speech audiometry consisted of obtaining the following measures: speech reception threshold, most comfortable listening level (MCL), and speech discrimination ability. The latter was determined by a live voice presentation of the Campbell Word List.

The otoadmittance meter was checked for calibration at the beginning of each test day. Tympanometry was administered using the GrasonStadler Model 1720, and the admittance values were plotted by means of a Hewlett-Packard, Model 7035B X-Y recorder. The values for conductance and susceptance were plotted for each of the two test frequencies, 220 and $660 \mathrm{~Hz}$, under conditions of decreasing ear canal pressure (from +200 to $-200 \mathrm{~mm} \mathrm{H}_{2}$ ).

The otoadmittance meter was used in the IAC room, although a sound-treated room is not necessary for the administration of tympanometry. The subject was seated in a chair facing the instrument, and the examiner explained the procedure to him as the test progressed. The subject was told to refrain from talking or moving, and to avoid any unnecessary swallowing, yawning, clearing of throat, or coughing. 
The subject was allowed to view the meters on the instrument. This reduced extraneous movements since he was able to note the needle movement caused by moving or swallowing.

After obtaining an airtight seal in the subject's ear, the first recording of susceptance was made at $220 \mathrm{~Hz}$, from conditions of positive to negative pressure, and then at $660 \mathrm{~Hz}$. The same procedure was used to record conductance at $220 \mathrm{~Hz}$ and $660 \mathrm{~Hz}$. The pressure was returned to the maximum value of admittance and the reflex thresholds were noted. The procecture was as follows: pure tones were presented via earphone to the ear opposite the probe tip. The otoadmittance meter was set to the $\triangle G B$ position which centers both meters and increases the sensitivity of the instrument. Tone presentation was administered in ascending $5 \mathrm{~dB}$ steps and the acoustic reflex threshold was determined if either meter showed a ten percent deflection of the needle to the left. Fifty ears of the eighty tested proved to be "normal" and were used in this investigation; sixteen ears or twenty percent of the sample produced tympanograms suggestive of a healed perforation. According to Jerger (1974), at least fifteen percent of "normals" display this "w" shaped tympanometric configuration. Nine ears in this sample produced configurations that were shallow or flat, or a tracing which was not within $50 \mathrm{~mm} \mathrm{H} \mathrm{H}_{2}$ of ambient air pressure; and a seal could not be obtained on five ears. From this sample of forty older adults, both ears of nineteen subjects were normal and were included in this study; twelve subjects had only one normal ear that could be utilized.

\section{Retesting}

Tympanometry was re-administered as a check of reliability within 
a two-week period to six of the subjects and a total of ten ears was utilized from this sample. One of the subjects reported a problem which was indicative of conductive pathology at one ear. Administration of tympanometry revealed the presence of conductive pathology, later confirmed by otoscopic examination. One ear of another subject proved impossible to seal during the retest session. 
CHAPTER IV

RESULTS AND DISCUSSION

$\underline{\text { Results }}$

The ranges for conductance and susceptance obtained from an older adult population are displayed in Figure 4 in template form. The upper and lower tracings at $0 \mathrm{~mm} \mathrm{H}_{2} \mathrm{O}$ pressure represent the $90 \mathrm{th}$ and $10 \mathrm{th}$ percentile points. TABLE II presents these same data plus the ranges and medians for admittance $\left(Y_{A}\right)$ and impedance $\left(Z_{A}\right)$. For comparative purposes, the figures obtained from one hundred normal ears (Feldman, 1974) are included on the table.

TABLE III includes group data for conductance, susceptance, admittance and impedance obtained from the older adult group. Included on the table are results reported by other researchers and obtained by them from "normal, young adult groups."

Means and standard deviations for reflex thresholds are shown in TABLE IV. Reflex thresholds were obtained at 500, 1000 and $2000 \mathrm{~Hz}$ and the data were averaged because there was no significant difference related to the stimulus frequency. Reflex thresholds were slightly better at the higher probe tone $(660 \mathrm{~Hz})$, but the difference between the 220 and $660 \mathrm{~Hz}$ probe tones was not significant. Similar data from Porter (1972) are displayed. He pointed out that the thresholds obtained using the $660 \mathrm{~Hz}$ probe were more acute than those from the $220 \mathrm{~Hz}$ probe, but that the largest difference was less than the usual $5 \mathrm{~dB}$ step utilized in clinical determination of thresholds. 


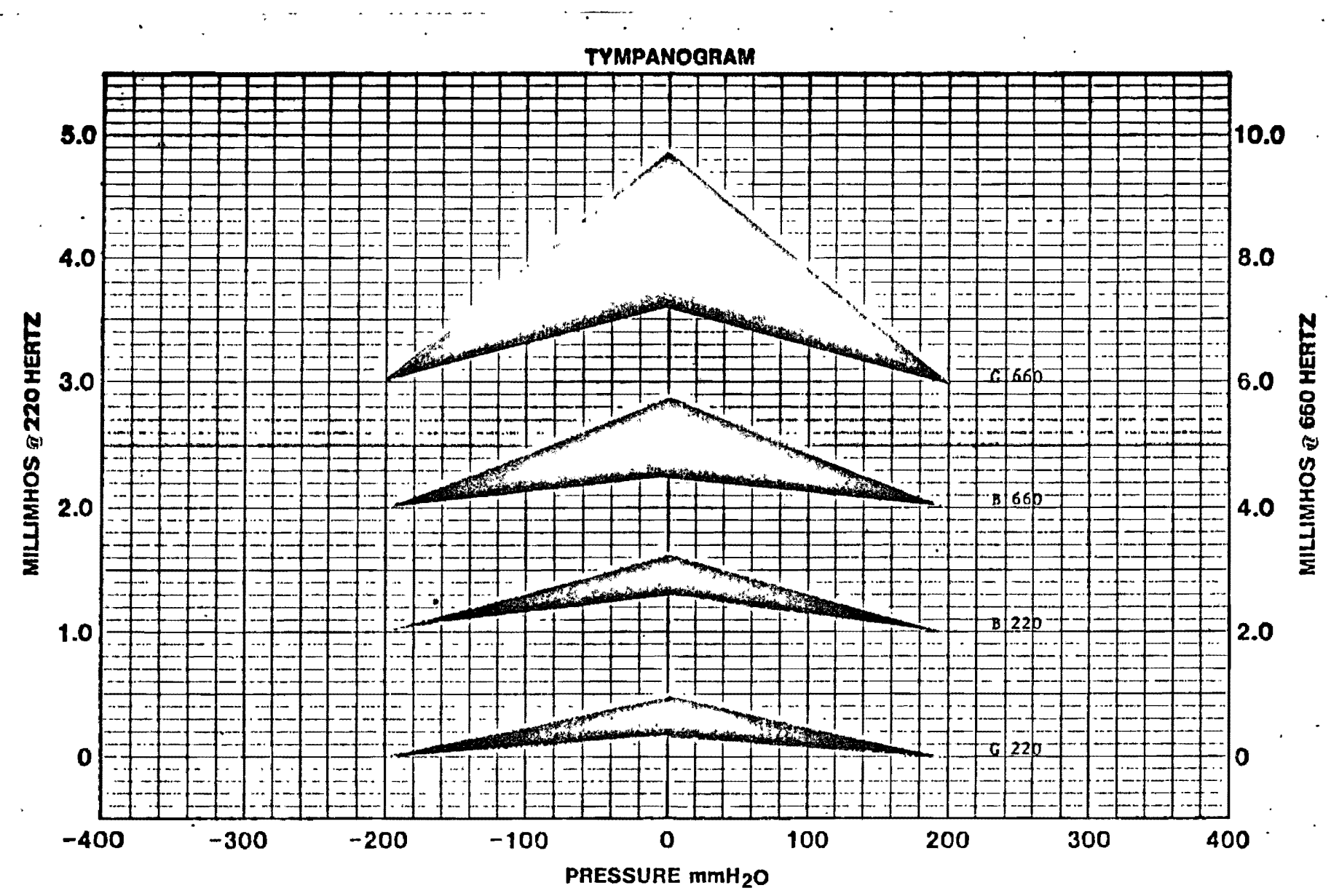

Figure 4. Ranges of 50 normal ears obtained from an older adult population. The upper and lower boundaries at $0 \mathrm{~mm} \mathrm{H} \mathrm{H}_{2} \mathrm{O}$ and $200 \mathrm{~mm} \mathrm{H}_{2} \mathrm{O}$ pressure are the $90 \mathrm{th}$ and loth percentile respectively. 
TABLE II

SUSCEPTANCE, CONDUCTANCE, ADMITTANCE IN MMHOS AND IMPEDANGE IN OHMS MEDIANS AND RANGES

\begin{tabular}{|c|c|c|c|c|c|c|c|c|}
\hline & & & $\mathrm{Hz}$ & & & & $0 \mathrm{~Hz}$ & \\
\hline & ${ }_{A}^{B}$ & $G_{A}$ & $Y_{A}$ & $Z_{A}$ & ${ }_{A}^{B}$ & $G_{A}$ & $Y_{A}$ & $Z_{A}$ \\
\hline $\begin{array}{l}50 \text { Normal Ear } \\
\text { (Fine) }\end{array}$ & & & & & & & & \\
\hline $80 \%$ Range & $.3-.65$ & $.15-.5$ & $.34-.74$ & $1240-1856$ & $.5-1.8$ & $1.2-3.8$ & $1.35-3.97$ & $252-735$ \\
\hline Medians & .5 & .3 & .58 & 1715 & 1.0 & 2.5 & 5.28 & 367 \\
\hline $\begin{array}{l}100 \text { Normal Ear } \\
\text { (Feldman, } 1974\end{array}$ & & & & & & & & \\
\hline $80 \%$ Range & $.3-.75$ & $.05-.35$ & $.33-.85$ & $1124-3048$ & $.9-2.45$ & $1.0-4.2$ & $1.38-4.5$ & $220-715$ \\
\hline Medians & .5 & .15 & .52 & 1856 & 1.3 & 1.95 & 2.43 & 409 \\
\hline
\end{tabular}




\section{TABLE III}

GROUP DATA FOR CONDUCTANCE, SUSCEPTANCE, ADMITTANCE IN MILLIMHOS, AND FOR IMPEDANCE IN OHMS

\begin{tabular}{|c|c|c|c|c|c|c|c|c|c|}
\hline & & $\begin{array}{c}\text { Cond. } \\
G_{A}\end{array}$ & $\begin{array}{c}\text { Susc. } \\
B_{A}\end{array}$ & $\begin{array}{c}\text { Admit. } \\
Y_{A}\end{array}$ & $\underset{Z_{A}}{\text { Imped. }}$ & $\begin{array}{c}\text { Cond. } \\
G_{A}\end{array}$ & $\begin{array}{c}\text { Susc. } \\
B_{A}\end{array}$ & $\begin{array}{c}\text { Admit } \\
Y_{A}\end{array}$ & ${ }_{Z_{A}}^{\text {Imped. }}$ \\
\hline \multirow{2}{*}{$\begin{array}{l}\text { Older Adults } \\
\text { (Fine) } \\
n=50 \text { ears } \\
59-83 \text { years }\end{array}$} & $\bar{x}$ & .32 & .49 & .59 & 1895 & 2.47 & 1.12 & 2.72 & 435 \\
\hline & $s_{.} d_{0}$ & .16 & .16 & .21 & 690 & 1.00 & .53 & 1.04 & 203 \\
\hline \multirow{2}{*}{$\begin{array}{l}\text { Young Adults } \\
\text { (Porter, 1972) } \\
n=36 \text { ears } \\
18-40 \text { years }\end{array}$} & $\bar{x}$ & .35 & .71 & .79 & 1265 & 2.75 & 1.01 & 2.93 & 341 \\
\hline & s.d. & .08 & .22 & - & - & 1.01 & .48 & - & - \\
\hline \multirow{2}{*}{$\begin{array}{l}\text { Young Adults } \\
\text { (Dirks \& Morgan, 1973) } \\
n=104 \text { ears }\end{array}$} & $\overline{\mathbf{x}}$ & .26 & .65 & .71 & 1616.1 & 1.91 & 1.29 & 2.34 & 509.4 \\
\hline & $s . d$. & .13 & .23 & .28 & 574.9 & 1.09 & .54 & 1.16 & 294.9 \\
\hline $\begin{array}{l}\text { Young Adults } \\
\text { (Jacobson et a1.,1973) }\end{array}$ & $\bar{x}$ & .28 & .58 & - & - & 1.7 & .83 & - & - \\
\hline $\begin{array}{l}n=60 \text { ears } \\
18-30 \text { years }\end{array}$ & s.d. & .24 & .23 & - & - & 1.0 & .50 & - & - \\
\hline
\end{tabular}


TABLE IV

GROUP DATA FOR ACOUSTIC REFLEX THRESHOLDS

\begin{tabular}{rlrcc} 
& \multicolumn{2}{c}{ Older Adults } & \multicolumn{2}{c}{ Adults } \\
& Fine & $\mathrm{n}=23$ & Porter (1972) & $\mathrm{n}=18$ \\
Probe tone & $\overline{\mathrm{x}}$ & s.d. & $\overline{\mathrm{X}}$ & s.d. \\
$220 \mathrm{~Hz}$ & 94.2 & 9.20 & 88.2 & 5.78 \\
$660 \mathrm{~Hz}$ & 92.9 & 9.15 & 85.9 & 6.20
\end{tabular}


Six of the forty subjects were retested within a two-week period using the same procedures as originally employed. Two of the subjects" ears were not included in this correlation: one appeared to have a mild middle ear infection in one ear resulting in a negative excursion in the tracing for that ear; the other subject had one ear upon which a seal could not be obtained. Therefore, from the six subjects, a total of ten ears were used. The means and standard deviations for these ten normal ears are shown on TABLE V. The results of the Pearson Product-Moment Correlation between the first and second test procedure revealed a high correlation and were significant at the levels shown.

Discussion

The ranges for $B_{A}$ and $G_{A}$ obtained from a normal older adult population are shown schematically on Figure 4. The upper and lower boundaries of each measurement represent the 90 th and 10 th percentile points at ambient atmospheric pressure. Measurements obtained from otologically normal older adults will fall within the limits displayed. The configurations do not necessarily portray the actual shape of the tympanogram obtained from changing air pressure in the ear canal.

The ranges and medians for $B_{A}, G_{A}, Y_{A}$, and $Z_{A}$ are reported on TABLE II, as well as those reported by Feldman (1974) for one hundred normal ears obtained from a younger sample. The median value of susceptance $\left(B_{A}\right)$ at $220 \mathrm{~Hz}$ is .5 mmo and agrees with Feldman's value of .5 obtained on one hundred normal young ears. The median values for the other measurements are in good agreement as well. Feldman stated that prior to his study, there were no reports of similar measurements with the otoadmittance meter. However, on TABLE III are gathered group 
TABLE V

10 NORMAL EARS, TEST - RETEST

Probe tone

frequency

B $220 \mathrm{~Hz}$

G $220 \mathrm{~Hz}$

Y $220 \mathrm{~Hz}$

Z $220 \mathrm{~Hz}$

B $660 \mathrm{~Hz}$

G $660 \mathrm{~Hz}$

Y $660 \mathrm{~Hz}$

$2660 \mathrm{~Hz}$

\section{Initial test}

$\overline{\mathbf{x}}$

.49

.29

.57

1886.5

1.19

2.57

2.69

428.8

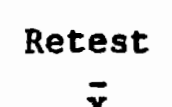

$\bar{x}$

.43

.29

.52

2192.1

1.06

2.27

2.55

420.0

\section{Initial Test}

s.d.

.13

.13

.16

602.9

.57

.89

.97

93.0
Retest

s.d.

.17

.09

.19

787.8

.51

.77

.74

108.5 r

$\begin{aligned} .765 & <.01 \\ .905 & <.001 \\ .874 & <.001 \\ .799 & <.01\end{aligned}$

.97

.85

.90

.73
$<.001$

$<.01$

$<.001$

$<.02$ 
data for these measurements as reported by Porter (1972), Dirks and Morgan (1973), Jacobson et al. (1973), as well as the older group investigated in this study. The latter three researchers utilized what they termed "normal young adult" populations. Upon surveying their results, it can be seen that there is a wide variance among the three studies, particularly those obtained with the $660 \mathrm{~Hz}$ probe tone. Porter (1972) found that the reflex thresholds obtained from his young normal group were slightly more acute using the $660 \mathrm{~Hz}$ probe tone. This was true with the older group as well, but not at a significant level. Some researchers believe that the higher frequency probe tones ( 660 or $800 \mathrm{~Hz}$ ) are preferable to $220 \mathrm{~Hz}$ because the change in impedance which occurs with the reflex muscle contraction is greater near the resonant frequency of the middle ear (M\$ller, 1960; Linden et al., 1972). However, Jerger (1974) found that by manipulating the probe tone frequency, there is a point at which the reflex disappears. In most normals, this occurs between 600 and $700 \mathrm{~Hz}$. Therefore, when investigating abnormalities in the acoustic reflex, the least desirable frequency range to use would be between 600 and $700 \mathrm{~Hz}$.

\section{Clinical Observations}

The results of this investigation on the aging are consistent with tympanometric values obtained by other investigators on normal young adults. This suggests that the otoadmittance meter is a valuable adjunct in the routine examination of older adults as well as in younger populations where it has already been established as a necessary part of the audiologic examination. In addition to the forty subjects selected to participate in this study, the otoadmittance meter has been 
used routinely in the assessment of older adults referred to Portland State University's Project ARM (Auditory Rehabilitation Mobile), a service designed to aid the low-income hard-of-hearing elderly.

The otoadmittance meter is relatively simple to operate and the complete recording of the tympanogram and the acoustic reflex thresholds for both ears can be completed in approximately twenty minutes. The procedure is not uncomfortable to the subject and an adequate seal can be quickly obtained in nearly all cases. Among the subjects used in this investigation, a seal could not be obtained in one female in one ear and in two male subjects in both ears. One of the latter subjects voluntarily returned to the clinic on three occasions, but a seal was not secured because of his abnormally large ear canals. In most cases, an adequate seal is obtained on the first attempt. One of the interesting aspects of this investigation related to the number of ears that were found, upon inspection, to be otologically normal, but whose tympanograms indicated the presence of a healed perforation. From the eighty ears included in this survey, sixteen produced configurations suggestive of a scarred tympanic membrane. The subjects claimed no memory of middle ear infection and scarring was not noted during otoscopic examination.

Ears having a healed perforation usually yield distinctive tympanograms. At $660 \mathrm{~Hz}$, the conductance $\left(G_{A}\right)$ curve will exhibit a large amplitude with a single peak and the susceptance curve $\left(B_{A}\right)$ will display a notch which may coincide with the conductance peak. Figure 5 is a schematic drawing of this type of tympanogram. In some cases, all four tracings will display sharp peaks. The greater amplitude of the configuration precludes measurement of conductance and susceptance 


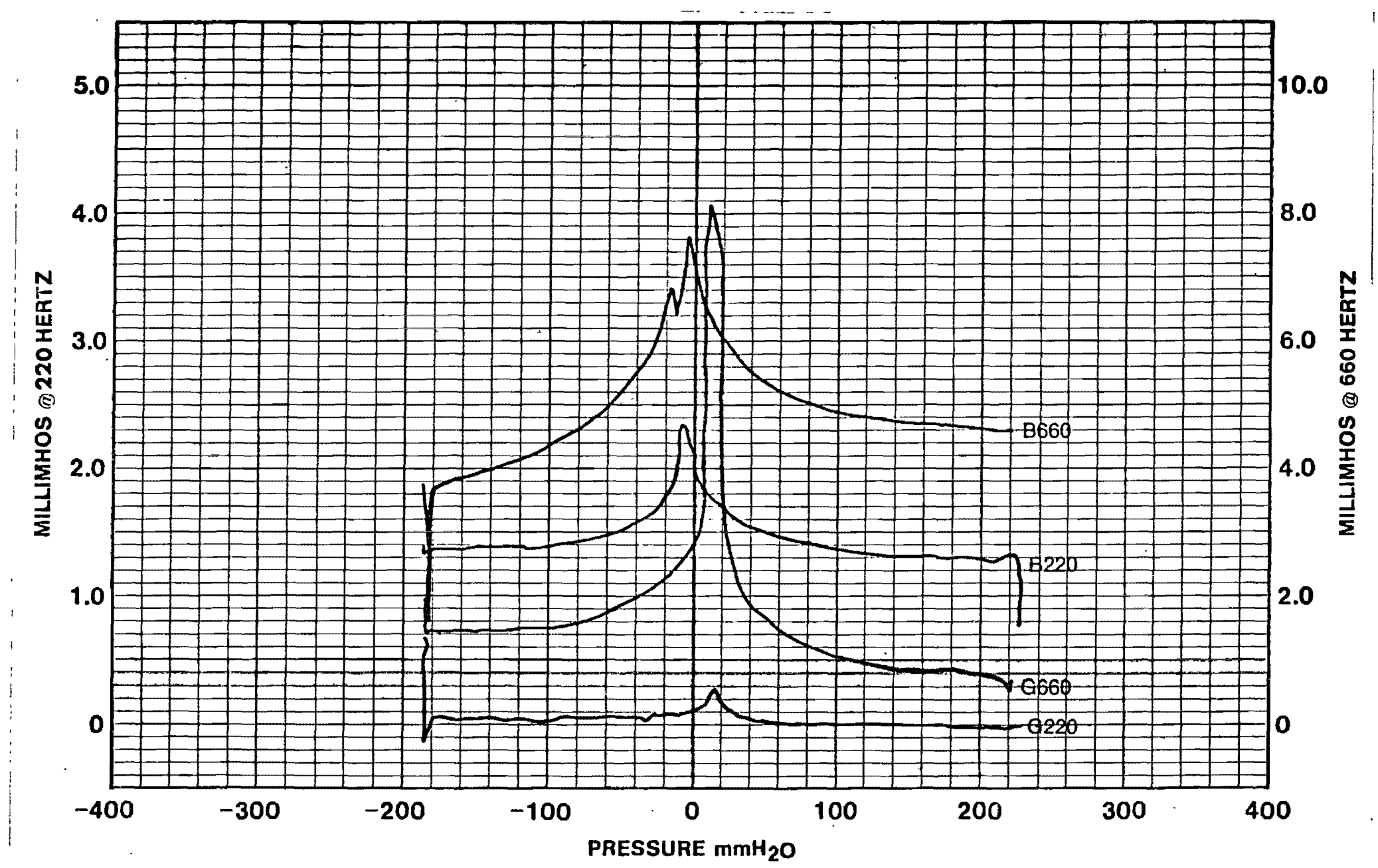

Figure 5. Tympanogram resulting from a healed perforation (0toadmittance Handbook 2, 1973). 
(static impedance), and invalidates the use of tympanometry in the differential diagnosis of middle ear pathologies.

\section{Research Implications}

Although the present investigation provides data on a small number of subjects, a larger sample should be utilized in order to establish additional normative data on an otologically normal older adult population. Research may be directed, not only toward between-subject, but between-ear measurements on this age group. Additionally, the reflex thresholds should be measured across the entire frequency range on normal young and normal older adult groups, and an analysis of variance made. These additional data would make possible the utilization of the otoadmittance meter for clinical use with aged subjects. 


\section{CHAPTER V}

\section{SUMMARY AND CONCLUSIONS}

Investigations utilizing electroacoustic measuring instruments designed to evaluate middle ear functioning have been made on children and on young adult populations. It appears, however, that there is no published research data available on tympanograms obtained from an elderly population. The results of the present study show that the use of tympanometry is valuable in the assessment of the status of the middle ear in the older adult as well as in younger populations. The purpose of the present study was to examine tympanometric configurations obtained from an otologically normal, older adult population. The information obtained may be used toward establishing working normative values using an otoadmittance meter.

The question under investigation was: What are the differences, if any, between tympanograms obtained from a normal young adult and those obtained from a normal older adult. Forty individuals were chosen to participate in this study. They ranged in age from 59 to 83 years of age and each had auditory acuity commensurate with his age. All of the subjects had a negative history of middle ear pathology and had normal tympanic membranes as determined by otologic examination. From the eighty ears tested, fifty were used in this survey. Four measurements were obtained at each ear: conductance and susceptance at $220 \mathrm{~Hz}$, and conductance and susceptance at $660 \mathrm{~Hz}$. For each subject, the $220 \mathrm{~Hz}$ probe tone was utilized first. The measurement 
under consideration was the amplitude of the curve obtained, and admittance was calculated from the conductance $\left(G_{A}\right)$ and susceptance $\left(B_{A}\right)$ components. Additionally, acoustic reflex thresholds were obtained from this population. The basis of these findings led to the following conclusions:

1) Tympanometry has been found to be a valuable adjunct in the assessment of the status of the middle ear in the older adult.

2) Results indicate that the values obtained for the measures of conductance and susceptance are comparable to those obtained from young adult groups.

3) The reflex thresholds are slightly higher (worse) in the older group than the younger group because their hearing thresholds are not as acute as those found in younger populations.

4) A larger percentage of the older population than might be expected was found to have evidence of healed perforations which were not found during otoscopic examination. These perforations affect the shape of the tympanometric configuration and may possibly obscure other pathologies.

The present investigation demonstrated that additional normative data are needed in order that the otoadmittance meter be fully utilized with older adult populations. 


\section{REFERENCES}

Brooks, D., An Objective Method of Determining Fluid in the Middle Ear. J. Int. Audiol., 7, 280-286, 1968.

- The Use of the Electro-Acoustic Impedance Bridge in the Assessment of Middle Ear Function. J. Int. Audiol., 8, 563-569, 1969.

Electroacoustic Impedance Bridge Studies on Normal Ears of Chíldren. J. Speech and Hearing Research, 14, 247-253, 1971.

Davis, H. and Silverman, S., Hearing and Deafness. New York: Holt, Rinehart and Winston, Inc., 1970.

Dirks, D. and Morgan, D., Application of Impedance Testing Procedures to Clinical Audiology. Presented at the North California Speech and Hearing Association Regional Meeting, 1973.

Feldman, A., Impedance Measurements at the Eardrum as an Aid to Diagnosis. J. Speech and Hearing Research, 6, 315-327, 1963.

- Acoustic Impedance Studies of the Normal Ear. J. Speech and Hearing Research, 10, 165-176, 1967.

- Eardrum Abnormality and the Measurement of Middle Ear Function. Arch. Otolaryngol., 99, 211-217, 1974.

Glorig, A, and Davis, H., Age Noise and Hearing Loss. Annals of Otol., Rhinol., and Laryngol., 70, 556-571, 1961.

Goetzinger, C., Proud, G., Dirks, D., and Embrey, J., A Study of Hearing in Advanced Age. Arch. Otolaryngol., 73, 662-674, 1961.

Goodhill, V., Bilateral Malleal Fixation and Conductive Presbycusis. Arch. Otolaryngol., 90, 759-764, 1969.

Hinchcliffe, R., The Anatomical Locus of Presbycusis. J. Speech and Hearing Research, 27, 301-310, 1962.

Jacobson, J., Kimmel, B., Fausti, S., Clinical Application of the Grason-Stadler Otoadmittance Meter. Unpublished Research Data, Veterans Administration Hospital, Portland, Oregon, 1973.

Jepsen, 0., Middle-ear Muscle Reflexes in Man, in J. Jerger (ed.) Modern Developments in Audiology. New York: Academic Press, 1963. 
Jerger, J., Clinical Experience with Impedance Audiometry. Arch Otolaryngol., 92, 311-324, 1970.

- Presentation on the Use of the Impedance Audiometer, Impedance Audiometry Seminar, Vancouver, B.C., June, 1974.

Klockoff, I. Middle-ear Muscle Reflexes in Man. Acta Otolaryngol. Suppl. 164, 1961.

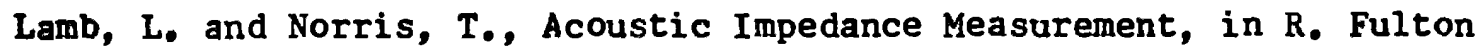
and L. Lloyd (eds.) Audiometry for the Retarded. Baltimore: The Williams and Wilkins Company, $1 \overline{969}$.

Lamb, L., Impedance measurement and the Middle Ear, Part III. Maico Audiological Library Series, 9, 1971.

Lilly, D., Measurement of Acoustic Impedance at the Tympanic Membrane.

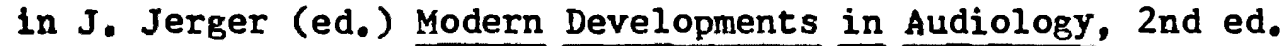
New York: Academic Press, 1973.

Linden, G., Bjorkman, G., and Peterson, J., Clinical Equipment for Measurement of Middle-ear Muscle Reflexes and Tympanometry. J. Speech and Hearing Disorders, 37, 100-112, 1972.

Metz, 0., The Acoustic Impedance Measured on Normal and Pathological Ears. Acta Otolaryngol., Suppl. 63, 1946.

Mbller, A., Improved Technique for Detailed Measurements of the Middle Ear Impedance. J. Acoustical Soc. Amer., 32, 250-257, 1960.

Newby, H., Audiology, 3rd ed. New York: Appleton-Century-Crofts, 1972.

Qtoadmittance Handbook 2, Grason-Stadler Co., Inc., 1973.

Porter, T., Normative Otoadmittance Values for Three Populations. J. Auditory Research, 12, 53-58, 1972.

Robertson, E., Peterson, J., and Lamb, L., Relative Impedance Measurements in Young Children. Arch. Otolaryngol., 88, 70-76, 1968.

Sataloff, J., Hearing Loss. Philadelphial J. B. Lippincott Co., 1966.

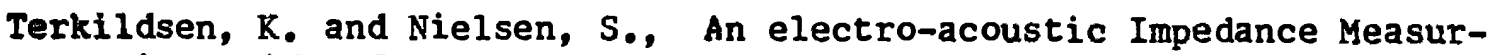
ing Bridge for Clinical Use. Arch. Otolaryngol., 72, 339-346, 1960.

Hebster, A., Acoustical Impedance, and the Theory of Horns and of the Phonograph. Proc. Nat. Acad. Sci., 5, 275-282, 1919.

Wever, E. and Lawrence, M., Physiological Acoustics. Princeton: Princeton University Press, 1954. 
Zemlin, W., Speech and Hearing Science. Englewood Cliffs, N.J.: Prentice-Hall, Inc., 1968.

Zwislocki, J., Some Impedance Measurements on Normal and Pathological Ears. J. Acoust. Soc. Amer., 29, 1312-1317, 1957.

, Acoustic Measurement of the Middle Ear Function. Annals Otol., Rhinol., Laryngol., 70, 599-606, 1961.

- An Acoustic Method for Clinical Examination of the Ear. J. Speech and Hearing Research, 6, 303-314, 1963.

and Feldman, A., Acoustic Impedance of Pathological Ears. ASHA Monograph, 非15, 1970. 